\title{
Are physical measures related to patient-centred outcomes in ARDS survivors?
}

\author{
Kitty S Chan, ${ }^{1}$ Lisa Aronson Friedman, ${ }^{2,3}$ Victor D Dinglas, ${ }^{2,3}$ Catherine L Hough, \\ Carl Shanholtz, ${ }^{5}$ E Wesley Ely, ${ }^{6,7}$ Peter E Morris, ${ }^{8}$ Pedro A Mendez-Tellez, ${ }^{2,9}$ \\ James C Jackson, ${ }^{6}$ Ramona $O$ Hopkins, ${ }^{10,11,12}$ Dale M Needham ${ }^{2,3,13}$
}

\begin{abstract}
- Additional material is published online only. To view please visit the journal online (http://dx.doi.org/10.1136/ thoraxjnl-2016-209400).
\end{abstract}

For numbered affiliations see end of article.

\section{Correspondence to}

Dr Kitty S Chan, Department of Health Policy and Management, Johns Hopkins Bloomberg School of Public Health, 624 North Broadway Room No 633, Baltimore, MD 21205-1901, USA; kchan10@jhu.edu

Received 8 September 2016 Revised 19 December 2016 Accepted 27 December 2016 Published Online First 20 January 2017

\section{SLinked}

- http://dx.doi.org/10.1136/ thoraxjnl-2016-209859

CrossMark

To cite: Chan KS, Aronson Friedman L, Dinglas VD, et al. Thorax 2017;72:884-892.

\section{ABSTRACT}

Objective To inform selection of physical measures for studies of acute respiratory distress syndrome (ARDS) survivors within 12 months of ARDS.

Methods Secondary analysis of data from 6-month survivors participating in a US multicentre prospective study (ARDSNet Long-Term Outcome Study, N=134) or a multisite prospective study in Baltimore, Maryland, USA (Improving Care of Acute Lung Injury Patients, $\mathrm{N}=99$ ). Physical measures, assessed at 6-month follow-up, were categorised according to the WHO's International Classification of Disability and Health: body functions and structures, activity and participation. Patient-centred outcomes were evaluated at 6 and 12 months: survival, hospitalisation, alive at home status and health-related quality of life. Pearson correlation, linear and logistic regression models were used to quantify associations of physical measures with patient-centred outcomes.

Main results No 6-month body functions and structures measure demonstrated consistent association with 6-month or 12-month outcomes in multivariable regression. The 6 min walk test, an activity measure, was associated with 6-month Short-Form 36 (SF-36) physical component scores (PCS, $\beta$ range: 0.99 to $1.52, p<0.05)$. Participation measures (Functional Performance Inventory, FPI; Instrumental Activities of Daily Living, IADLs) were associated with SF-36 PCS ( $\beta$ range: FPI, 1.51-1.52; IADL, -1.88 to -1.32 ; all $p<0.05$ ) and Euro-Q0L-5D utility score ( $\beta$ range: $F P I, 2.00-3.67 ;$ IADL, -2.89 to -2.50 ; all $p<0.01$ ) at 6 and 12 months.

Conclusions Participation measures better reflect patient's quality of life than measures of body functions and structures within 12 months of ARDS among 6-month survivors, and are recommended for inclusion as a core measure in future studies.

\section{INTRODUCTION}

Survivors of acute respiratory distress syndrome (ARDS) frequently experience long-lasting physical impairments. ${ }^{1}$ Clinical research in this patient population have used a wide range of performancebased and patient-reported physical measures, from evaluations of muscle mass and strength to the performance of activities of daily living (ADL). ${ }^{2}$ This heterogeneity contributes to problems with interpreting and synthesising evidence across studies. ${ }^{3}$ Bringing greater consistency to outcomes measurement is an important methodological challenge for critical care research. ${ }^{3-5}$

\section{Key messages}

What is the key question?

- Which physical measures are informative of current and future patient-centred outcomes in survivors during their first year of recovery after acute respiratory distress syndrome (ARDS)?

\section{What is the bottom line?}

- No measure of body functions and structures (eg, muscle strength) were associated with 12-month quality of life. Participation measures (eg, instrumental activities of daily living) are associated with quality of life and are recommended for future studies focused on evaluating and improving these outcomes in ARDS survivors.

\section{Why read on?}

- This study provides detailed empirical analyses to directly compare a wide range of physical status measures based on their associations with important patient-centred outcomes, including survival to 12 months, hospitalisation, being alive at home and health-related quality of life to help identify a core set of physical status measures for future studies of ARDS survivors.

Physical measures, particularly performancebased measures, such as manual muscle testing (MMT) and the 6 min walk test, have demonstrated reliability and validity in ARDS and other groups of intensive care unit (ICU) survivors. ${ }^{6} 7$ In addition, inpatient measures of muscle strength were associated with mortality by 90 days $^{8}$ and 1 year $^{9}$ in critically ill patients. This literature is an important start for identifying core outcome measures. However, there is limited empirical research with head-to-head comparisons of physical measures to help researchers determine the optimal measures for evaluating postdischarge outcomes of ARDS survivors.

The current analysis will directly compare performance-based and patient-reported physical measures used in two different studies of ARDS survivors, based on independent associations with a range of patient-centred outcomes (ie, survival, 
hospitalisation, alive at home status and health-related quality of life (HRQL)), assessed concurrently and in the subsequent 6 months. Our goal is to help inform the selection of a minimum set of physical measures for future clinical research studies in the field. Among 6-month survivors of ARDS, we examined the associations of physical measures assessed at 6-month follow-up with 6-month and 12-month patient-centred outcomes. Physical measures are categorised according to the WHO's International Classification of Functioning, Disability and Health (ICF) framework to help evaluate how useful measures from different categories within the ICF framework are for inferring a range of patient-centred outcomes.

\section{METHODS}

\section{Study design and data sources}

Secondary analyses were performed using data from two studies, the ARDSNet Long-Term Outcome Study (ALTOS) and the Improving Care of Acute Lung Injury Patients (ICAP) study. ${ }^{10} 11$ ALTOS included ARDS survivors from 12 hospitals across five study sites in the USA. ${ }^{10}$ ALTOS subjects were recruited based on participation in at least one of three co-enrolling randomised trials, conducted by the National Heart, Lung and Blood Institute ARDS Network, evaluating aerosolised albuterol versus placebo (ALTA trial), ${ }^{12}$ early versus delayed enteral feeding (EDEN trial) ${ }^{13}$ and omega- 3 fatty acid and antioxidant supplement versus placebo (OMEGA trial). ${ }^{14}$ ICAP was a prospective cohort study that included ARDS survivors from 13 ICUs in four academic teaching hospitals in Baltimore, Maryland, USA. ${ }^{11}$ Patients who survive to 6 months and have follow-up at 6 and 12 months are included in this analysis. Participants missing data on any 6-month physical measure were excluded from analysis. Analyses of 12-month patientcentred outcomes, excluding survival, are conducted among 12-month survivors.

\section{Measures}

Our analysis focused on physical measures and patient-centred outcomes that were available in the ALTOS and ICAP studies, and recommended or used in prior studies of physical outcomes in acute respiratory failure (ARF)/ARDS survivors. ${ }^{1} 215$

\section{Patient-centred outcomes}

A range of patient-centred outcomes were available and selected for inclusion in this analysis. These outcomes included death and any hospitalisation between 6 and 12 months' follow-up, as well as alive at home status at 6 and 12 months among those who resided at home at baseline $(1=$ patient returned to living at home; $0=$ patient at another care facility or died between 6 and 12 months for the 12-month outcome) and HRQL at 6 and 12 months' follow-up. Data on survival (12-month), hospitalisation and alive at home status were obtained via patient or proxy report, as well as search of publicly available data sources (including the Social Security Death Index ${ }^{16}$ ) for the mortality outcome. Patient-reported HRQL was evaluated using the Medical Outcomes Study Short-Form 36 survey V.2 (SF-36) ${ }^{17}$ physical component score (PCS) and the EQ-5D-3L ${ }^{18}{ }^{19}$ utility score.

\section{Physical measures}

Physical measures, including performance-based and patientreported assessments, were evaluated at 6-month follow-up and categorised as body functions and structures, activity and participation according to the ICF framework. ${ }^{20}$ Body functions and structures were measured by a range of clinical assessments performed in both studies. Pulmonary function was assessed using spirometry ${ }^{21}$ and reported as per cent predicted $\mathrm{FEV}_{1}$ using normative values. ${ }^{22}$ In the study protocol for ICAP, spirometry was not performed at 6-month follow-up if already assessed at 3-month follow-up. Therefore, 3-month $\mathrm{FEV}_{1}$ values were used for ICAP subjects missing 6-month values. Overall muscle strength was assessed by MMT and scored according to Medical Research Council criteria ${ }^{23} 24$ (range, $0-60$, with $<48$ indicating 'ICU-acquired weakness' ${ }^{25}$ ) and by percentage of predicted value for hand grip strength. ${ }^{26}$ Maximal inspiratory pressure (MIP), a measure of respiratory muscle strength, ${ }^{27} 28$ and upper arm anthropometric assessment of per cent muscle, ${ }^{29} 30$ which was calculated based on the mean of three triceps skinfold and three midarm circumference measurements, were also evaluated. Activity was represented by the $4 \mathrm{~m}$ gait speed (ALTOS only) and the 6 min walk test (6MWT, both studies). The $4 \mathrm{~m}$ gait speed was performed and scored according to published standards. ${ }^{31}$ The $6 \mathrm{MWT}$, as a percentage of the predicted value, was performed based on the American Thoracic Society (ATS) guidelines ${ }^{32}$ with modest variation, including performing a single $6 \mathrm{MWT}$ at each followup (as done in prior ARDS research ${ }^{1}$ ) and using the longest available distance (based on ATS guidelines ${ }^{32}$ ) during home visits. Participation was represented by patient reports of $\mathrm{ADLs}^{33}$ and Instrumental Activities of Daily Living (IADLs) ${ }^{34}$ in the ICAP study, and the Functional Performance Inventory $(\mathrm{FPI})^{35}$ overall score in ALTOS.

\section{Statistical analysis}

Identical statistical analyses were performed for ALTOS and ICAP. For the bivariable analyses, data from the two studies were also combined to maximise sample size and statistical power.

\section{Bivariable analyses}

Associations between 6-month physical measures with 6-month and 12-month patient-centred outcomes were quantified using Pearson correlation coefficients for continuous outcomes (ie, SF-36 PCS, EQ-5D utility score) and unadjusted logistic regression analysis for binary outcomes (ie, survival to 12 months and alive at home status).

\section{Multivariable analyses}

We used multivariable regression models to test the independent associations of 6-month physical measures with each 6-month and 12-month patient-centred outcome. Linear regression models were used for SF-36 PCS and EQ-5D utility scores, and logistic regression models were used for survival, hospitalisation and alive at home status. These associations were examined separately for ICAP and ALTOS. All models included percentage predicted $\mathrm{FEV}_{1}$, percent muscle area, MIP, MMT, hand grip and 6MWT. In ICAP models, ADLs and IADLs were also included, while $4 \mathrm{~m}$ gait speed and FPI were added to ALTOS models. As a sensitivity analysis, we included baseline age, gender, race, body mass index, Charlson Comorbidity Index and Functional Comorbidity Index in these models to examine the robustness of the associations observed (data available upon request). Variance inflation factors were computed for each multivariable regression model to assess for multicollinearity. ${ }^{36}$ Loess graphs were inspected to confirm that linear models are appropriate for modelling the relationship between each physical assessment and patient-centred outcome. SAS V.9.4 was used for all analyses.

We also calculated standardised estimates for regression models to facilitate comparison of the strength of association 
across 6-month physical measures. Estimates for physical measures are standardised to the scale of the outcome in each model. These data are provided in an online supplement (see online supplementary tables A1-A4).

\section{RESULTS}

Patient characteristics were similar between ALTOS and ICAP in 6-month survivors (table 1), although ICAP had a higher proportion of black participants and longer lengths of stay, and a higher proportion of ALTOS patients had pneumonia. At 6 months, survivors from both studies had similar muscle strength, with ALTOS survivors having modestly higher $\mathrm{FEV}_{1}$ per cent predicted, lower arm muscle area and higher per cent predicted 6MWT.

Survivors from both studies had comparable alive at home status and HRQL scores at both follow-ups, and relatively few deaths occurring between 6 and 12 months. A modestly larger proportion of ALTOS's 6-month survivors did not have a hospital readmission between 6 and 12 months.

\section{Unadjusted associations with Concurrent (6-month) patient-centred outcomes}

There were no statistically significant associations between being alive at home at 6 months and either body functions or structures measures in either study (table 2). However, these measures were positively correlated with 6-month HRQL outcomes (Pearson $\mathrm{r} \leq 0.38$ ), with MMT and grip strength demonstrating consistent association with SF-36 PCS in both ICAP and ALTOS. Activity measures 6MWT and $4 \mathrm{~m}$ gait speed were consistently associated with HRQL outcomes in both studies (Pearson $r \geq 0.34$, all $\mathrm{p}<0.01$ ). Participation measures, IADL in ICAP and FPI in ALTOS, were significantly correlated with both HRQL outcomes (Pearson $r$ range: -0.46 to -0.38 for IADL; $0.59-0.63$ for FPI, all $\mathrm{p}<0.01$ ).

\section{Unadjusted associations with Future (12-month) patient-centred outcomes}

Among 12-month survivors, manual muscle test assessed at 6 months was significantly associated with SF-36 PCS at 12 months, but few other 6-month body functions and structures measures were consistently associated with 12-month outcomes across the two studies (table 3). Activity measures (6MWT and $4 \mathrm{~m}$ gait speed) and participation measures (IADL and FPI) were consistently and positively associated with both HRQL outcomes in the following 6 months (all $\mathrm{p}<0.01$ ). Significant correlation with survival status, hospitalisation and being alive at home in the subsequent 6 months was also observed with 6MWT, $4 \mathrm{~m}$ gait speed and IADL, but these associations were not consistently observed in both studies.

\section{Independent associations with Concurrent (6-month) patient-centred outcomes}

No body functions and structures measures at 6 months demonstrated independent associations with 6-month outcomes in both studies (table 4). The lack of consistent association of muscle strength measures (MMT, MIP and hand grip) with the SF-36 PCS, a physically oriented HRQL outcome, was particularly noteworthy. In contrast, the 6MWT was associated with the SF-36 PCS in both studies. Participation measures, IADL in ICAP and FPI in ALTOS, were associated with both HRQL outcomes. Multicollinearity was not observed across the ICF measures, including for the ADL and IADL measures, indicating distinct independent associations with the patient-centred outcomes for these two participation measures. With few
Table 1 ARDS survivor characteristics by study*

\begin{tabular}{|c|c|c|}
\hline Baseline variables & $\begin{array}{l}\text { ICAP } \\
(\mathrm{N}=99)\end{array}$ & $\begin{array}{l}\text { ALTOS } \\
(\mathrm{N}=134)\end{array}$ \\
\hline \multicolumn{3}{|l|}{ Demographic and clinical characteristics } \\
\hline Age, years, mean (SD) & $48.2(14.0)$ & $48.9(14.6)$ \\
\hline Male, n (\%) & $55(55.6)$ & $68(50.7)$ \\
\hline $\mathrm{BMI}, \mathrm{kg} / \mathrm{m}^{2}$, mean (SD) & $28.3(6.8)$ & $31.0(7.8)$ \\
\hline \multicolumn{3}{|l|}{ Race, n (\%) } \\
\hline White & $58(59.2)$ & $121(90.3)$ \\
\hline Black & $39(39.8)$ & $9(6.7)$ \\
\hline Other & $1(1.0)$ & $4(3.0)$ \\
\hline \multicolumn{3}{|l|}{ Primary lung injury, $\mathrm{n}(\%)$} \\
\hline Pneumonia & $48(50.0)$ & $85(66.9)$ \\
\hline Sepsis & $18(18.8)$ & $20(15.7)$ \\
\hline Aspiration & $11(11.5)$ & $11(8.7)$ \\
\hline Trauma & $5(5.2)$ & $6(4.7)$ \\
\hline Transfusions & $5(5.2)$ & $5(3.9)$ \\
\hline Other & $9(9.4)$ & $0(0)$ \\
\hline Charlson Comorbidity Index, mean (SD) & $2.0(2.2)$ & $1.1(1.7)$ \\
\hline Functional Comorbidity Index, mean (SD) & $1.5(1.4)$ & $1.8(1.3)$ \\
\hline APACHE II score, mean (SD) $\dagger$ & $23.8(8.2)$ & $25.4(7.8)$ \\
\hline Ventilation duration, days, mean (SD) & $12.7(12.5)$ & $11.3(10.1)$ \\
\hline ICU length of stay, days, mean (SD) & $17.8(17.3)$ & $15.1(11.9)$ \\
\hline Hospital length of stay, days, mean (SD) & $29.4(22.8)$ & $22.2(16.3)$ \\
\hline \multicolumn{3}{|l|}{ 6-month physical measuresł } \\
\hline \multicolumn{3}{|l|}{ Body structure and function measures } \\
\hline $\mathrm{FEV}_{1}$, mean \% predicted (SD) & $71.5(18.9)$ & $78.8(18.6)$ \\
\hline Arm muscle area, mean \% (SD) & $52.3(12.3)$ & $44.7(18.1)$ \\
\hline MIP, mean \% predicted (SD) & $83.8(35.2)$ & $91.1(31.0)$ \\
\hline MMT, mean \% maximum MRC score (SD) & $91.1(8.7)$ & $92.5(7.3)$ \\
\hline Hand grip strength, mean \% predicted (SD) & $77.7(24.5)$ & $78.5(25.2)$ \\
\hline \multicolumn{3}{|l|}{ Activity measures } \\
\hline 6MWT, mean \% predicted (SD) & $58.5(20.1)$ & $67.2(19.7)$ \\
\hline $4 \mathrm{~m}$ gait speed, mean (SD) in m/s (ALTOS only) & - & $1.0(0.3)$ \\
\hline \multicolumn{3}{|l|}{ Participation measures } \\
\hline $\begin{array}{l}\text { Number of ADL dependencies, mean (SD) (range } \\
0-6, \text { ICAP only) }\end{array}$ & $0.2(0.8)$ & - \\
\hline $\begin{array}{l}\text { Number of IADL dependencies, mean (SD) (range } \\
0-8 \text {, ICAP only) }\end{array}$ & $1.8(2.1)$ & - \\
\hline $\begin{array}{l}\text { FPI-total score, mean (SD) (range: } 0-2 \text {, } \\
\text { ALTOS only) }\end{array}$ & - & $2.0(0.6)$ \\
\hline \multicolumn{3}{|l|}{ 6-month patient-centred outcomes $\ddagger$} \\
\hline Alive and living at home, $\mathrm{n}(\%)$ & $92(96.8)$ & $125(94.0)$ \\
\hline SF-36 PCS score, mean (SD) & $39.7(11.3)$ & $38.5(11.6)$ \\
\hline EQ-5D utility score, mean (SD) & $0.8(0.2)$ & $0.7(0.2)$ \\
\hline \multicolumn{3}{|l|}{ 12-month patient-centred outcomesł } \\
\hline Alive to 12 months, $n(\%)$ & $95(96.0)$ & $129(96.3)$ \\
\hline No hospitalisation, $\mathrm{n}(\%)$ between 6 and 12 months & $59(72.8)$ & $98(78.4)$ \\
\hline Alive and living at home, $\mathrm{n}(\%)$ & $88(93.6)$ & $120(90.2)$ \\
\hline SF-36 PCS score, mean (SD) & $41.4(10.5)$ & $41.4(12.8)$ \\
\hline EQ-5D utility score, mean (SD) & $0.8(0.2)$ & $0.7(0.2)$ \\
\hline
\end{tabular}

*Only patients with ARDS who survive to 6-month follow-up are included in this study. tEstimated APACHE II score based on conversion from APACHE III to APACHE II. ${ }^{40}$ $\ddagger$ Based on non-missing values; Missing values - 6-month physical measures (none for any variable in both studies); 6 -month outcome (alive at home, $N=4,4 \%$ for ICAP, $\mathrm{N}=1,0.7 \%$ for ALTOS; SF-36 PCS, N=0 for ICAP and ALTOS; EQ-5D, N=0 for ICAP, $\mathrm{N}=1,0.7 \%$ for ALTOS); 12 -month outcomes (alive to 12 months, $\mathrm{N}=0$ for ICAP and ALTOS; no hospitalisation, $\mathrm{N}=18,18.2 \%$ for ICAP, $\mathrm{N}=9,6.7 \%$ for ALTOS; alive at home, $\mathrm{N}=5,5.0 \%$ for ICAP, $\mathrm{N}=1,0.7 \%$ for ALTOS; SF-36 PCS, N=9, 9.1\% for ICAP $\mathrm{N}=10,7.5 \%$ for ALTOS; EQ-5D, N=8, 8.1\% for ICAP, $N=9,6.7 \%$ for ALTOS) ADL, activities of daily living; ALTOS, ARDSNet Long-Term Outcome Study; APACHE, Acute Physiology and Chronic Health Evaluation; ARDS, acute respiratory distress syndrome; BMI, body mass index; EQ-5D, Euro-QOL; FPI, Functional Performance Inventory; IADL, instrumental activities of daily living; ICAP, Improving Care of Acute Lung Injury Patients; ICU, intensive care unit; MIP, maximal inspiratory pressure; MMT, manual muscle testing; MRC, Medical Research Council; QOL, Quality of Life; 6MWT, 6 min walk test; SF-36 Medical Outcomes Study Short-Form 36 physical component score. 
Table 2 Bivariable associations of 6-month physical measures with 6-month patient-centred outcomes

\begin{tabular}{|c|c|c|c|}
\hline \multirow[b]{2}{*}{ 6-month physical measures } & \multirow[b]{2}{*}{$\begin{array}{l}\text { Alive at homet } \\
\text { OR }(95 \% \mathrm{Cl})\end{array}$} & \multicolumn{2}{|l|}{ Health-related quality of life } \\
\hline & & $\begin{array}{l}\text { SF-36 PCS } \\
\text { Pearson r }(95 \% \mathrm{Cl})\end{array}$ & $\begin{array}{l}\text { EQ-5D utility } \\
\text { Pearson } \mathrm{r}(95 \% \mathrm{Cl})\end{array}$ \\
\hline \multicolumn{4}{|l|}{ Body structure and function measures } \\
\hline \multicolumn{4}{|l|}{$\mathrm{FEV}_{1}$, each $10 \%$ predicted } \\
\hline Combined sample & $1.03(0.75$ to 1.41$)$ & $0.19(0.06 \text { to } 0.31)^{* *}$ & $0.08(-0.05$ to 0.21$)$ \\
\hline ICAP & $1.30(0.74$ to 2.29$)$ & $0.10(-0.10$ to 0.29$)$ & $-0.01(-0.21$ to 0.19$)$ \\
\hline ALTOS & $0.98(0.66$ to 1.44$)$ & $0.27(0.11 \text { to } 0.42)^{* *}$ & $0.18(0.01 \text { to } 0.34)^{*}$ \\
\hline \multicolumn{4}{|l|}{ Arm muscle area, each $10 \%$} \\
\hline Combined sample & $1.11(0.79$ to 1.55$)$ & $0.16(0.04 \text { to } 0.29)^{*}$ & $0.18(0.05 \text { to } 0.30)^{* *}$ \\
\hline ICAP & 1.57 (0.66 to 3.76$)$ & $0.27(0.08 \text { to } 0.44)^{* *}$ & $0.14(-0.06$ to 0.32$)$ \\
\hline ALTOS & $1.00(0.67$ to 1.48$)$ & $0.10(-0.07$ to 0.27$)$ & $0.16(-0.01$ to 0.32$)$ \\
\hline \multicolumn{4}{|l|}{ MIP, each $10 \%$ predicted } \\
\hline Combined sample & $1.04(0.86$ to 1.25$)$ & $0.20(0.08 \text { to } 0.32)^{* *}$ & $0.15(0.02 \text { to } 0.27)^{*}$ \\
\hline ICAP & $1.11(0.77$ to 1.60$)$ & $0.12(-0.08$ to 0.31$)$ & $0.08(-0.12$ to 0.27$)$ \\
\hline ALTOS & $1.02(0.81$ to 1.29$)$ & $0.28(0.12 \text { to } 0.43)^{* *}$ & $0.23(0.06 \text { to } 0.38)^{* *}$ \\
\hline \multicolumn{4}{|l|}{ MMT, each $10 \%$ of maximum MRC score } \\
\hline Combined sample & 1.42 (0.73 to 2.77$)$ & $0.32(0.20 \text { to } 0.43)^{* *}$ & $0.25(0.12 \text { to } 0.36)^{*}$ \\
\hline ICAP & $2.02(0.72$ to 5.68$)$ & $0.28(0.09 \text { to } 0.45)^{* *}$ & $0.17(-0.03$ to 0.35$)$ \\
\hline ALTOS & 1.20 (0.48 to 3.01$)$ & $0.38(0.22 \text { to } 0.51)^{* *}$ & $0.33(0.17 \text { to } 0.48)^{* *}$ \\
\hline \multicolumn{4}{|l|}{ Grip strength, each $10 \%$ predicted } \\
\hline Combined sample & 1.05 (0.82 to 1.35$)$ & $0.19(0.06 \text { to } 0.31)^{* *}$ & $0.11(-0.02$ to 0.24$)$ \\
\hline ICAP & $1.21(0.71$ to 2.05$)$ & $0.21(0.02 \text { to } 0.39)^{*}$ & $0.10(-0.10$ to 0.29$)$ \\
\hline ALTOS & 1.01 (0.76 to 1.34$)$ & $0.17(0.00 \text { to } 0.33)^{*}$ & $0.12(-0.05$ to 0.29$)$ \\
\hline \multicolumn{4}{|l|}{ Activity measures } \\
\hline \multicolumn{4}{|l|}{$6 \mathrm{MWT}$, each $10 \%$ predicted } \\
\hline Combined sample & $1.44(1.08 \text { to } 1.92)^{*}$ & $0.43(0.32 \text { to } 0.53)^{* *}$ & $0.34(0.22 \text { to } 0.45)^{* *}$ \\
\hline ICAP & $2.00(1.12 \text { to } 3.58)^{*}$ & $0.43(0.25 \text { to } 0.58)^{* *}$ & $0.37(0.19 \text { to } 0.53)^{* *}$ \\
\hline ALTOS & $1.36(0.94$ to 1.95$)$ & $0.48(0.33 \text { to } 0.60)^{* *}$ & $0.38(0.22 \text { to } 0.52)^{* *}$ \\
\hline $4 \mathrm{~m}$ gait speed, each $0.11 \mathrm{~m} / \mathrm{s} \ddagger$ (ALTOS only) & $1.11(0.83$ to 1.48$)$ & $0.46(0.32 \text { to } 0.59)^{* *}$ & $0.44(0.29 \text { to } 0.56)^{* *}$ \\
\hline \multicolumn{4}{|l|}{ Participation measures } \\
\hline Number of ADL dependencies (ICAP only) & $0.56(0.30$ to 1.04$)$ & $-0.06(-0.26$ to 0.14$)$ & $-0.10(-0.29$ to 0.10$)$ \\
\hline Number of IADL dependencies (ICAP only) & 0.66 (0.40 to 1.08$)$ & $-0.46(-0.60 \text { to }-0.29)^{* *}$ & $-0.38(-0.54 \text { to }-0.20)^{* *}$ \\
\hline FPI—total, per 0.20 unit§ (ALTOS only) & $1.19(0.95$ to 1.50$)$ & $0.59(0.46 \text { to } 0.69)^{* *}$ & $0.63(0.52 \text { to } 0.72)^{* *}$ \\
\hline
\end{tabular}

exceptions, models including baseline variables produced comparable results.

\section{Independent associations with Future 12-month patient-centred outcomes}

None of the 6-month physical measures demonstrated significant independent association with survival or hospitalisation status in the next 6 months (table 5). $\mathrm{FEV}_{1}$ was associated with being alive at home at 12 months, although the direction of the association differed in ICAP and ALTOS. Patient-reported participation measures, IADL in ICAP and FPI in ALTOS, were associated with both 12-month HRQL outcomes. Grip strength and 6MWT were also significantly associated with HRQL, but these associations were observed in only one of the two studies. Sensitivity analyses based on models with patient demographic and clinical variables were generally comparable.

\section{DISCUSSION}

Using two multisite, longitudinal clinical studies of ARDS survivors, our study provides empirical data among 6-month survivors on the associations of physical measures with a range of patient-centred outcomes (ie, survival, hospitalisation, alive at home and HRQL). Our focus on the performance of several widely used physical measures will be informative for current efforts to determine the core outcome sets ${ }^{4} 5$ for this population.

Few measures of body functions and structures (eg, muscle area and three different measures of muscle strength) were independently associated with 6-month and 12-month outcomes. Furthermore, these associations were not consistently observed across the two studies. However, patient-reported participation measures, IADL and FPI, demonstrated independent associations with both HRQL outcomes at 6 and 12 months. Performance-based 6MWT was independently associated with the 6-month physically oriented SF-36 PCS outcome in both studies, but was only associated with the broader EQ-5D outcome in ICAP at 6 months. Significant independent associations of participation measures with future survival, hospitalisation and alive at home status were observed, although these associations were not consistently observed in both studies. 
Table 3 Bivariable associations of 6-month physical measures with 12-month patient-centred outcomes

\begin{tabular}{|c|c|c|c|c|c|}
\hline 6-month physical measures & $\begin{array}{l}\text { Alive between } 6 \\
\text { and } 12 \text { monthst } \\
\text { OR }(95 \% \mathrm{Cl})\end{array}$ & $\begin{array}{l}\text { No hospitalisation } \\
\text { between } 6 \text { and } \\
12 \text { months } ¥ \\
\text { OR }(95 \% \mathrm{CI})\end{array}$ & $\begin{array}{l}\text { Alive at home at } \\
12 \text { months§ } \\
\text { OR (95\% CI) }\end{array}$ & $\begin{array}{l}\text { SF-36 PCS } 12 \text { months } \\
\text { Pearson } \mathrm{r}(95 \% \mathrm{Cl})\end{array}$ & $\begin{array}{l}\text { EQ-5D utility } 12 \text { months } \\
\text { Pearson } r(95 \% \mathrm{Cl})\end{array}$ \\
\hline \multicolumn{6}{|l|}{ Body structure and function measures } \\
\hline \multicolumn{6}{|l|}{$\mathrm{FEV}_{1}$, each $10 \%$ predicted } \\
\hline Combined sample & $1.11(0.79$ to 1.55$)$ & $1.08(0.92$ to 1.28$)$ & 1.00 (0.78 to 1.28$)$ & $0.18(0.05 \text { to } 0.31)^{* *}$ & $0.02(-0.11$ to 0.15$)$ \\
\hline ICAP & $1.78(1.05 \text { to } 3.04)^{*}$ & 0.84 (0.63 to 1.12$)$ & $1.72(1.10 \text { to } 2.71)^{*}$ & $0.12(-0.09$ to 0.32$)$ & $-0.09(-0.29$ to 0.12$)$ \\
\hline ALTOS & 0.68 (0.39 to 1.20$)$ & $1.27(1.01 \text { to } 1.59)^{*}$ & 0.75 (0.53 to 1.06$)$ & $0.22(0.04 \text { to } 0.38)^{*}$ & $0.11(-0.07$ to 0.28$)$ \\
\hline \multicolumn{6}{|l|}{ Arm muscle area, each $10 \%$} \\
\hline Combined sample & $1.04(0.70$ to 1.54$)$ & $0.93(0.76$ to 1.14$)$ & $1.12(0.86$ to 1.45$)$ & $0.08(-0.05$ to 0.22$)$ & $0.09(-0.05$ to 0.22$)$ \\
\hline ICAP & $0.64(0.25$ to 1.60$)$ & $0.87(0.59$ to 1.30$)$ & $0.53(0.24$ to 1.20$)$ & $0.24(0.03 \text { to } 0.42)^{*}$ & $0.17(-0.04$ to 0.36$)$ \\
\hline ALTOS & 1.20 (0.79 to 1.82$)$ & $0.98(0.77$ to 1.24$)$ & 1.22 (0.93 to 1.60$)$ & $0.03(-0.15$ to 0.20$)$ & $0.03(-0.15$ to 0.20$)$ \\
\hline \multicolumn{6}{|l|}{ MIP, each $10 \%$ predicted } \\
\hline Combined sample & 1.21 (0.96 to 1.51$)$ & 1.04 (0.94 to 1.14$)$ & 1.09 (0.94 to 1.26$)$ & $0.15(0.02 \text { to } 0.28)^{*}$ & $0.03(-0.10$ to 0.17$)$ \\
\hline ICAP & 1.31 (0.89 to 1.93$)$ & $1.03(0.90$ to 1.18$)$ & 1.12 (0.86 to 1.45$)$ & $0.01(-0.19$ to 0.22$)$ & $-0.18(-0.37$ to 0.03$)$ \\
\hline ALTOS & 1.15 (0.85 to 1.54$)$ & $1.04(0.90$ to 1.19$)$ & 1.09 (0.91 to 1.32$)$ & $0.25(0.07 \text { to } 0.41)^{* *}$ & $0.20(0.02 \text { to } 0.36)^{*}$ \\
\hline \multicolumn{6}{|c|}{ MMT, each $10 \%$ of maximum MRC score } \\
\hline Combined sample & $0.97(0.41$ to 2.28$)$ & $1.21(0.81$ to 1.82$)$ & $1.44(0.86$ to 2.43$)$ & $0.32(0.19 \text { to } 0.43)^{* *}$ & $0.23(0.10 \text { to } 0.36)^{* *}$ \\
\hline ICAP & $1.33(0.48$ to 3.70$)$ & $1.04(0.57$ to 1.90$)$ & 1.23 (0.51 to 2.95$)$ & $0.34(0.14 \text { to } 0.51)^{* *}$ & $0.03(-0.18$ to 0.23$)$ \\
\hline ALTOS & 0.59 (0.13 to 2.67$)$ & 1.39 (0.80 to 2.40$)$ & 1.69 (0.85 to 3.36$)$ & $0.31(0.14 \text { to } 0.46)^{* *}$ & $0.41(0.25 \text { to } 0.54)^{* *}$ \\
\hline \multicolumn{6}{|l|}{ Grip strength, each $10 \%$ predicted } \\
\hline Combined sample & $0.90(0.70$ to 1.16$)$ & 1.08 (0.95 to 1.24$)$ & 0.98 (0.82 to 1.19$)$ & $0.08(-0.05$ to 0.21$)$ & $0.05(-0.09$ to 0.18$)$ \\
\hline ICAP & $0.97(0.65$ to 1.44$)$ & $1.17(0.94$ to 1.46$)$ & 0.97 (0.69 to 1.35$)$ & $0.08(-0.13$ to 0.28$)$ & $-0.10(-0.30$ to 0.11$)$ \\
\hline ALTOS & $0.86(0.62$ to 1.19$)$ & $1.03(0.87$ to 1.22$)$ & $0.99(0.79$ to 1.24$)$ & $0.09(-0.09$ to 0.26$)$ & $0.13(-0.05$ to 0.30$)$ \\
\hline \multicolumn{6}{|l|}{ Activity measures } \\
\hline \multicolumn{6}{|l|}{$6 \mathrm{MWT}$, each $10 \%$ predicted } \\
\hline Combined sample & $1.16(0.84$ to 1.59$)$ & $1.27(1.08 \text { to } 1.50)^{* *}$ & $1.13(0.90$ to 1.41$)$ & $0.42(0.30 \text { to } 0.53)^{* *}$ & $0.23(0.10 \text { to } 0.35)^{* *}$ \\
\hline ICAP & 1.21 (0.76 to 1.91$)$ & $1.20(0.94$ to 1.54$)$ & 1.14 (0.77 to 1.67$)$ & $0.43(0.24 \text { to } 0.58)^{* *}$ & $0.22(0.02 \text { to } 0.41)^{*}$ \\
\hline ALTOS & $1.12(0.71$ to 1.75$)$ & $1.32(1.05 \text { to } 1.67)^{*}$ & 1.17 (0.88 to 1.56$)$ & $0.44(0.28 \text { to } 0.57)^{* *}$ & $0.28(0.11 \text { to } 0.44)^{* *}$ \\
\hline $\begin{array}{l}4 \mathrm{~m} \text { gait speed, each } 0.11 \mathrm{~m} / \mathrm{s} \| \\
\text { (ALTOS only) }\end{array}$ & $0.91(0.71$ to 1.17$)$ & $1.29(1.06 \text { to } 1.58)^{*}$ & 1.01 (0.82 to 1.24$)$ & $0.42(0.27 \text { to } 0.56)^{* *}$ & $0.34(0.17 \text { to } 0.48)^{* *}$ \\
\hline \multicolumn{6}{|l|}{ Participation measures } \\
\hline $\begin{array}{l}\text { Number of ADL dependencies } \\
\text { (ICAP only) }\end{array}$ & $0.67(0.35$ to 1.29$)$ & $0.90(0.52$ to 1.53$)$ & $0.76(0.39$ to 1.45$)$ & 0.01 ( -0.19 to 0.22$)$ & $0.00(-0.21$ to 0.20$)$ \\
\hline $\begin{array}{l}\text { Number of IADL dependencies } \\
\text { (ICAP only) }\end{array}$ & $0.55(0.34 \text { to } 0.91)^{*}$ & $1.13(0.87$ to 1.47$)$ & $0.69(0.49 \text { to } 0.98)^{*}$ & $-0.38(-0.54 \text { to }-0.18)^{* *}$ & $-0.29(-0.47 \text { to }-0.09)^{* *}$ \\
\hline $\begin{array}{l}\text { FPI-total, per } 0.20 \text { unitt } \dagger \\
\text { (ALTOS only) }\end{array}$ & $0.96(0.71$ to 1.30$)$ & 1.14 (0.99 to 1.32$)$ & 1.16 (0.96 to 1.39$)$ & $0.50(0.36 \text { to } 0.62)^{* *}$ & $0.42(0.26 \text { to } 0.55)^{* *}$ \\
\hline
\end{tabular}

${ }^{*} p<0.05 ;{ }^{* *} p<0.01$.

tAlive between 6 and 12 months (yes=1, no=0; combined-1, $n=224,96 \% ; 0, n=9,4 \% ;$ ICAP-1, $n=95,96 \% ; 0, n=4,4 \% ;$ ALTOS-1, $n=129,96 \% ; 0, n=5,4 \%$ ).

₹No hospitalisation between 6 and 12 months (yes=1, no=0; combined-1, $n=157,76 \% ; 0, n=49,24 \% ;$ ICAP-1, $n=59,73 \% ; 0, n=22,27 \% ; A L T O S-1, n=98,78 \% ; 0, n=27,22 \%$ ).

$\S$ Alive at home outcome for 12 months (yes=1, no=0; combined-1, $n=208,92 \%, 0, n=19,8 \% ;$ ICAP-1, $n=88,94 \%, 0, n=6,6 \% ; A L T O S-1, n=120,90 \% ; 0, n=13,10 \%$ ).

$90.11 \mathrm{~m} / \mathrm{s}$ is an estimated MCID for the $4 \mathrm{~m}$ gait speed test based on prior study among patients with COPD. ${ }^{31}$

t+0.20 is an estimated MCID for the FPI.

ADL, activities of daily living; ALTOS, ARDSNet Long-Term Outcome Study; EQ-5D, Euro-QOL; FPI, Functional Performance Inventory; IADL, instrumental activities of daily living; ICAP, Improving Care of Acute Lung Injury Patients; MCID, minimal clinically important difference; MIP, maximal inspiratory pressure; MMT, manual muscle testing; MRC, Medical Research

Council; QOL, Quality of Life; 6MWT, 6 min walk test; SF-36 PCS, Medical Outcomes Study Short-Form 36 physical component score.

These results suggest that the participation measures we examined may be more useful than measures of body functions and structures (eg, MIP and MMT) for inferring concurrent 6-month and future 12-month HRQL. Specifically, for researchers interested in these patient-centred outcomes, our findings provide validity evidence supporting the use of the IADL or FPI patient-reported measures in future follow-up studies of ARDS survivors. The performance-based $6 \mathrm{MWT}$ may be useful for researchers more focused on the physical aspects of patient functioning and quality of life of ARDS survivors. The lack of significant independent associations for ADLs likely reflects that few patients experience impairments in these basic activities by 6-month follow-up. This low variation in ADLs across patients would limit the measure's associations with 6-month and 12-month patient-centred outcomes during the posthospitalisation recovery period.

Our findings may be helpful in future studies when limited time and resources warrant selection of a reduced battery of physical measures. It is important to note that while some measures, such as MIP or grip strength, were not independently associated with the patient-centred outcomes evaluated in our study, these measures can still provide valuable information on specific aspects of health targeted by the test, or possibly on patient-centred outcomes not examined in our study. The physical measures we recommended based on our empirical findings are intended to support current efforts to identify a minimum set of outcome measures that all studies in this field would use (ie, a 'core outcome set'). ${ }^{5}$ For studies that aim to elucidate 


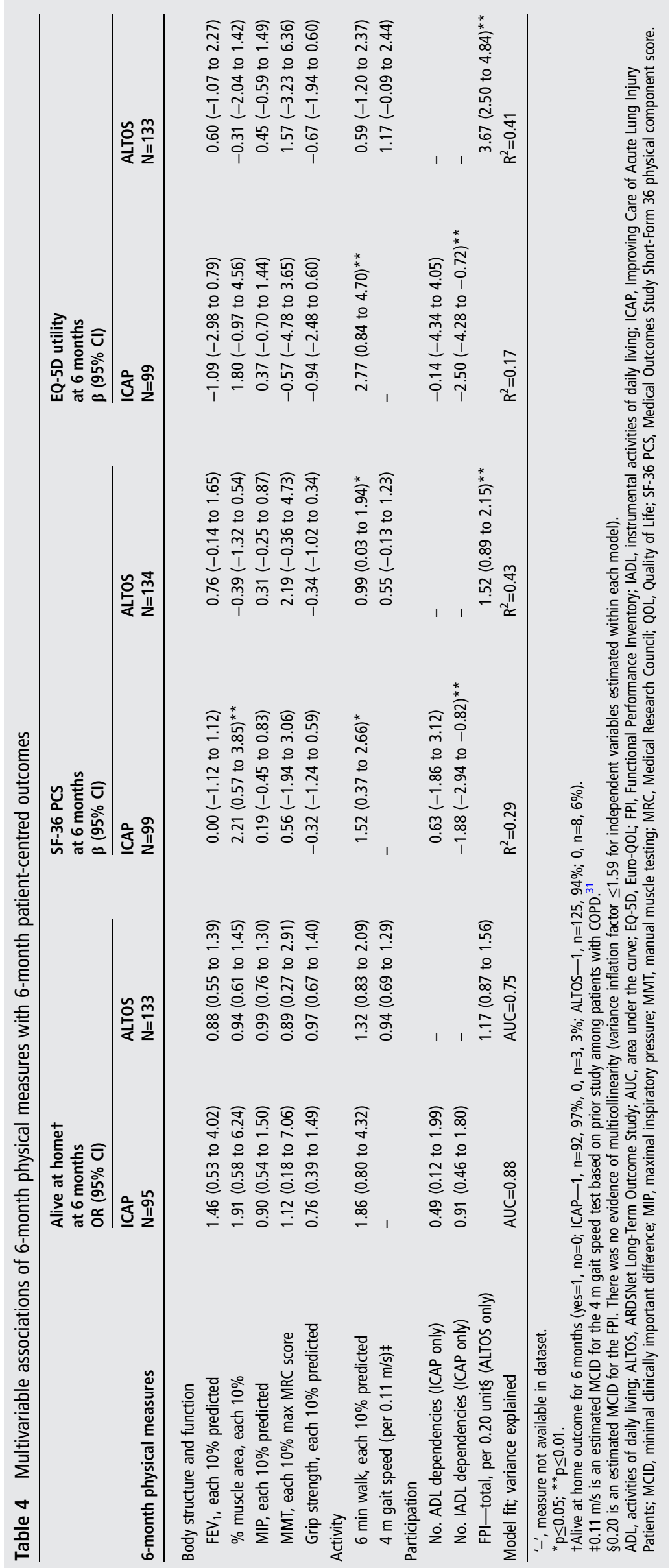




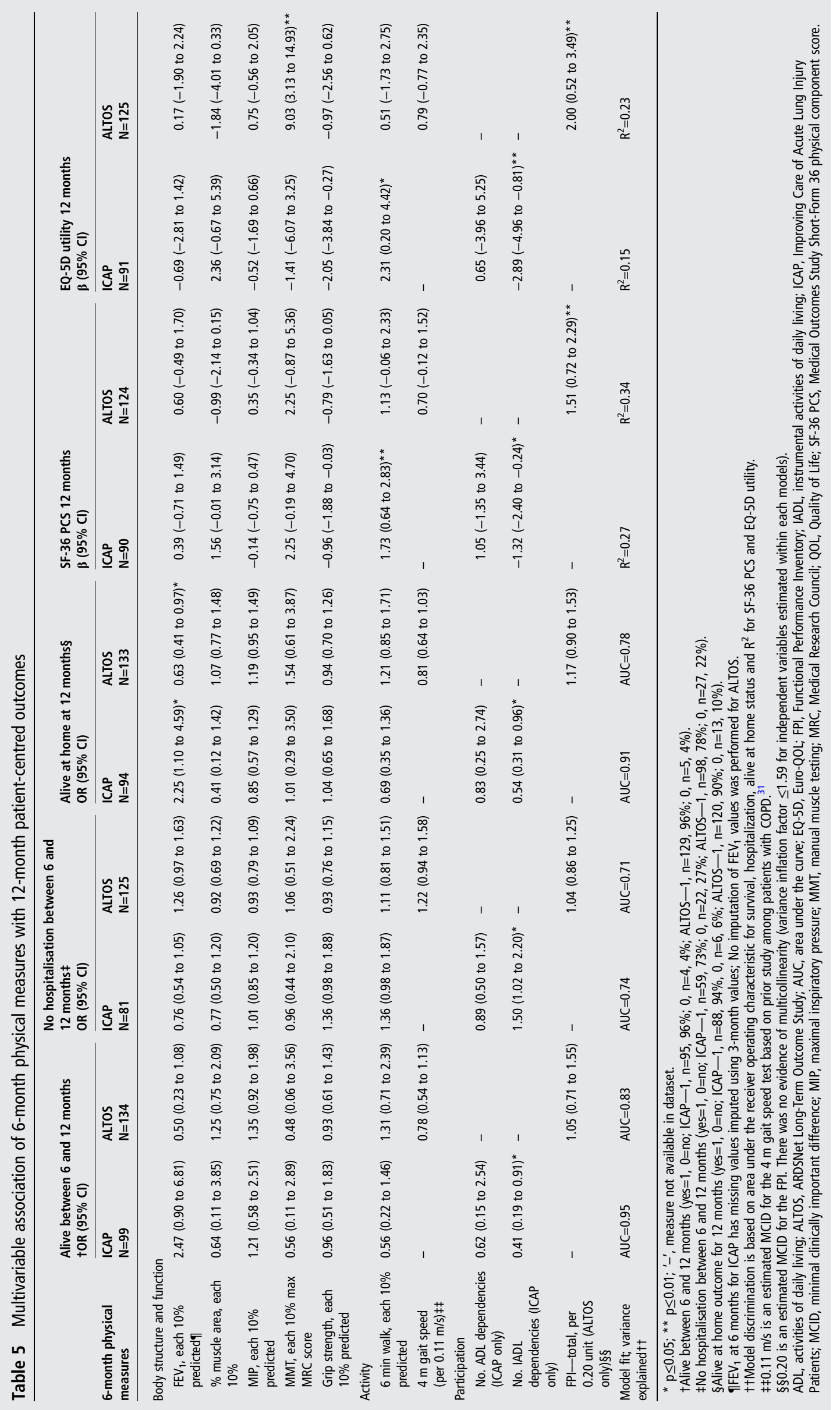


mechanism of action of a treatment, the inclusion of relevant physical and other mechanistic measures, as well as patientcentred outcomes, may be beneficial in understanding how the intervention exerts its effect.

Whether a measure is informative of an outcome of interest is an important criterion during measure selection. However, other criteria, including feasibility, ${ }^{37}$ are important to consider. Notably, performance-based activity measures have greater resource needs than self-reported participation measures. For instance, although our findings suggest that 6MWT and IADLs are both informative of patient HRQL, the 6MWT requires an in-person visit, basic equipment, appropriate physical surroundings and substantial time (at least $21 \mathrm{~min}$ for a single test given the required pretest rest break, ${ }^{38}$ to perform the test). In contrast, the self-reported IADLs can be administered in 2-3 min via a survey or telephone interview. ${ }^{39}$ For researchers interested in the patient-centred outcomes examined in our study, IADLs may be more suitable, particularly when in-person visits are not feasible, as in some national multicentre studies.

The general lack of association between measures of body functions and structures with the patient-centred outcomes evaluated in our study is an important finding. In prior studies, muscle weakness during hospitalisation has been associated with outpatient mortality. ${ }^{8}{ }^{9}$ However, our analyses were focused on selecting postdischarge physical measures, evaluated at 6-month follow-up, rather than in-hospital measures. This difference in findings at these time points suggests that the value of particular physical measures for inferring patient-centred outcomes may change over the course of a patient's recovery. ${ }^{11}$ In addition, the patient-centred outcomes examined in our study are influenced by numerous health and environmental factors, particularly in the postdischarge period, which individual anatomical or physiological tests are unlikely to adequately reflect. It is important to note that while we observed that study measures within the same ICF domain (eg, body functions and structures) appear to demonstrate similar relationships, or lack of relationships, with outcomes, our findings are limited to the specific measures we examined. We cannot infer that comparable associations would be observed for other measures within the same ICF domain.

Our study also highlights challenges of using physical measures to infer some patient-centred outcomes in the posthospitalisation period. Few of the physical measures at 6 months demonstrated significant independent associations with survival, hospitalisation or alive at home status. The lack of association with survival may be due, in part, to relatively few deaths observed after 6-month follow-up in both studies. For the alive at home outcome, many non-physical issues including those described as 'environmental factors' in the ICF framework, ${ }^{20}$ such as the availability of caregivers and home-based environmental adaptations (eg, installation of a ramp instead of stairs to enter the home setting), can influence this outcome.

This study has important strengths, including empirically evaluating the independent association of a wide range of physical measures with multiple patient-centred outcomes at 6 and 12 months. Many measures, especially those for body functions and structures, were available in two independent studies, allowing for comparison of findings across different samples of ARDS survivors. However, our study has several limitations. First, some activity and participation measures were included only in one study; hence, we could not evaluate generalisability of findings for these specific measures in both studies. Second, this study focused on 6-month survivors and the association of 6-month physical measures with 6-month and 12-month patient-centred outcomes in ARDS survivors in the USA; hence, the findings may not generalise to other patient populations, other time points in ARDS survivors' recovery or other patient-centred outcomes. Future research is needed to confirm our findings in other samples of survivors of critical illness, including non-US samples for international generalisability. Third, while we conducted sensitivity analysis of our findings by including baseline demographic and clinical variables in our multivariable analyses, we did not have the data to examine other potentially important variables such as pre-ICU functional status and HRQL. Therefore, we cannot determine the degree to which the observed associations between the physical measures and outcomes are influenced by a patient's preexisting health or functional status. Fourth, we used complete case analysis in our study, which could have introduced bias for our study estimates, as patients with complete data may be healthier in general. Finally, our study modelled the physical measures as continuous variables. Although the appropriateness of this modelling of the physical measures was confirmed for purposes of regression modelling, it was beyond the scope of this analysis to attempt to determine how to optimally model each physical measure with each patient-centred outcome examined in this study.

\section{CONCLUSION}

Bringing greater consistency to outcomes measurement is an important methodological challenge for critical care research. ${ }^{3-5}$ For clinical researchers, selecting physical measures for studies of ARDS survivors over their first 12 months of recovery and participation measures such as IADLs will more closely reflect patient HRQL than measures of body functions and structures.

\section{Author affiliations}

${ }^{1}$ Department of Health Policy and Management, Johns Hopkins Bloomberg School of Public Health, Baltimore, Maryland, USA

${ }^{2}$ Outcomes after Critical Illness and Surgery Group, Johns Hopkins University School of Medicine, Baltimore, Maryland, USA

${ }^{3}$ Division of Pulmonary and Critical Care Medicine, Johns Hopkins University School of Medicine, Baltimore, Maryland, USA

${ }^{4}$ Division of Pulmonary and Critical Care Medicine, Harborview Medical Center,

University of Washington, Seattle, Washington, USA

${ }^{5}$ Division of Pulmonary and Critical Care Medicine, University of Maryland,

Baltimore, Maryland, USA

${ }^{6}$ Division of Allergy, Pulmonary, and Critical Care Medicine, Department of Medicine, Vanderbilt University School of Medicine, Nashville, Tennessee, USA

${ }^{7}$ Geriatric Research, Education and Clinical Center Service, Department of Veterans Affairs Medical Center, Tennessee Valley Healthcare System, Nashville, Tennessee, USA

${ }^{8}$ Division of Pulmonary, Critical Care and Sleep Medicine, University of Kentucky, Lexington, Kentucky, USA

${ }^{9}$ Department of Anesthesiology and Critical Care Medicine, Johns Hopkins University School of Medicine, Baltimore, Maryland, USA

${ }^{10}$ Department of Medicine, Pulmonary and Critical Care Division, Intermountain Medical Center, Murray, Utah, USA

${ }^{11}$ Center for Humanizing Critical Care, Intermountain Health Care, Murray, Utah, USA

${ }^{12}$ Psychology Department and Neuroscience Center, Brigham Young University, Provo, Utah, USA

${ }^{13}$ Department of Physical Medicine and Rehabilitation, Johns Hopkins University School of Medicine, Baltimore, Maryland, USA

Acknowledgements The authors thank Dr Elizabeth Colantuoni for guidance on the statistical methods used in this study.

Contributors KSC and DMN contributed to study conception and design. VDD CLH, CS, PEM, PAM-T, JCJ, ROH and DMN contributed data for the study. LAF conducted analyses, and all authors contributed to analysis and interpretation. KSC drafted the manuscript, and all other authors critically revised it for important intellectual content. All authors approved the submitted manuscript. KSC and DMN are responsible for the overall content and affirm that the manuscript is an accurate 
account of the reported study and that no important aspects of the study have been omitted.

Funding This research was supported by the National Heart, Lung and Blood Institute (R24 HL111895, R01HL091760, R01HL091760-02S1, R01HL096504, R01HL88045 and P050HL73994), the Johns Hopkins Institute for Clinical and Translational Research (UL1 TR 000424-06), and the ALTA and EDEN/OMEGA trials (contracts for sites participating in this study: HSN268200536170C, HHSN268200536171C, HHSN268200536173C, HHSN268200536174C, HSN268200536175C and HHSN268200536179C).

Competing interests None declared.

Ethics approval Institutional Review Board.

Provenance and peer review Not commissioned; externally peer reviewed.

\section{REFERENCES}

1 Herridge MS, Tansey CM, Matté A, et al. Functional disability 5 years after acute respiratory distress syndrome. N Engl J Med 2011;364:1293-304.

2 Turnbull AE, Rabiee A, Davis WE, et al. Outcome measurement in ICU survivorship research from 1970-2013: a scoping review of 425 publications. Crit Care Med 2016:44:1267-77.

3 Blackwood B, Clarke M, McAuley DF, et al. How outcomes are defined in clinical trials of mechanically ventilated adults and children. Am J Respir Crit Care Med 2014;189:886-93.

4 Needham DM. Understanding and improving clinical trial outcome measures in acute respiratory failure. Am J Respir Crit Care Med 2014;189:875-7.

5 Blackwood B, Marshall J, Rose L. Progress on core outcome sets for critical care research. Curr Opin Crit Care 2015;21:439-44.

6 Parry SM, Granger CL, Berney $\mathrm{S}$, et al. Assessment of impairment and activity limitations in the critically ill: a systematic review of measurement instruments and their clinimetric properties. Intensive Care Med 2015;41:744-62.

7 Chan KS, Pfoh ER, Denehy L, et al. Construct validity and minimal important difference of 6-minute walk distance in survivors of acute respiratory failure. Chest 2015;14:1316-26.

8 Hodgson C, Bellomo R, Berney S, et al., The TEAM Study Investigators. Early mobilization and recovery in mechanically ventilated patients in the ICU: a bi-national, multi-centre, prospective cohort study. Crit Care 2015;19:81.

9 Hermans G, Van Mechelen H, Clerckx B, et al. Acute outcomes and 1-year mortality of intensive care unit-acquired weakness. A cohort study and propensity-matched analysis. Am J Respir Crit Care Med 2014;190:410-20.

10 Needham DM, Wozniak AW, Hough CL, et al. Risk factors for physical impairment after acute lung injury in a national, multi-center study. Am J Respir Crit Care Med 2014;189:1214-24

11 Fan E, Dowdy DW, Colantuoni E, et al. Physical complications in acute lung injury survivors: a two-year longitudinal prospective study. Crit Care Med 2014;42:849-59.

12 Matthay MA, Brower RG, Carson S, et al. Randomized, placebo-controlled clinical trial of an aerosolized $\beta_{2}$-agonist for treatment of acute lung injury. Am J Respir Crit Care Med 2011;184:561-8.

13 Rice TW, Wheeler AP, Thompson BT, et al. Initial trophic vs full enteral feeding in patients with acute lung injury: the EDEN randomized trial. JAMA J Am Med Assoc 2012:307:795-803

14 Rice TW, Wheeler AP, Thompson BT, et al. Enteral omega-3 fatty acid, gamma-linolenic acid, and antioxidant supplementation in acute lung injury. JAMA 2011:306:1574-81.

15 Angus DC, Carlet J. Surviving intensive care: a report from the 2002 Brussels Roundtable. Intensive Care Med 2003:29:368-77.

16 Social Security Death Index. http://ssdi.rootsweb.ancestry.com/cgi-bin/ssdi.cgi (accessed 13 Jan 2011).
17 Ware JE, Snow KK, Kosinski M, et al. SF-36 Health Survey Manual and Interpretation Guide. 1993. http://books.google.com/books/about/SF_36_health_ survey.html?id=WJsgAAAAMAAJ

18 Williams A. EuroQol-A new facility for the measurement of health-related quality of life. Health Policy 1990;16:199-208.

19 Shaw JW, Johnson JA, Coons SJ. US valuation of the EQ-5D health states: development and testing of the D1 valuation model. Med Care 2005;43:203-20.

20 World Health Organization. International classification of functioning, disability and health. Geneva: World Health Organization, 2001.

21 Miller MR, Hankinson J, Brusasco V, et al. Standardisation of spirometry. Eur Respir J 2005:26:319-38.

22 Hankinson JL, Odencrantz JR, Fedan KB. Spirometric reference values from a sample of the general U.S. population. Am J Respir Crit Care Med 1999;159: 179-87.

23 Fan $E$, Ciesla ND, Truong $A D$, et al. Inter-rater reliability of manual muscle strength testing in ICU survivors and simulated patients. Intensive Care Med 2010:36:1038-43.

24 Medical Research Council. Aids to the investigation of the peripheral nervous system. London: Her Majesty's Stationary Office, 1976.

25 De Jonghe $B$, Sharshar $T$, Lefaucheur JP, et al. Paresis acquired in the intensive care unit: a prospective multicenter study. JAMA 2002;288:2859-67.

26 Mathiowetz V, Kashman N, Volland G, et al. Grip and pinch strength: normative data for adults. Arch Phys Med Rehabil 1985;66:69-74.

27 American Thoracic Society/European Respiratory Society. Statement on respiratory muscle testing. Am J Respir Crit Care Med 2002;166:518-624.

28 Harik-Khan RI, Wise RA, Fozard JL. Determinants of maximal inspiratory pressure: the Baltimore longitudinal study of aging. Am J Respir Crit Care Med 1998;158(Pt 1):1459-64.

29 Frisancho AR. Anthropometric standards for the assessment of growth and nutritional status. Ann Arbor, Ml: University of Michigan Press, 1990.

30 Centers for Disease Control and Prevention (CDC). National Health and Nutrition Examination Survey (NHANES): Anthropometric Procedures Manual. Hyattsville MD: US Department of Health and Human Services \& Centers for Disease Control and Prevention, 2009

31 Kon SSC, Canavan JL, Nolan CM, et al. The 4-metre gait speed in COPD: Responsiveness and minimal clinically important difference. Eur Respir J 2014:43:1298-305.

32 American Thoracic Society Committee on Proficiency Standards for Clinical Pulmonary Function Laboratories. ATS statement: guidelines for the six-minute walk test. Am J Respir Crit Care Med 2002;166:111-17.

33 Katz S, Ford AB, Moskowitz RW, et al. Studies of illness in the aged. J Am Med Assoc 1963;185:914-19.

34 Lawton MP, Brody EM. Assessment of older people: self-maintaining and instrumental activities of daily living. Gerontologist 1969:9:179-86.

35 Leidy NK. Psychometric properties of the functional performance inventory in patients with chronic obstructive pulmonary disease. Nurs Res 1999:48:20-8. http:/l ovidsp.ovid.com/ovidweb.cgi?T=JS\&CSC=Y\&NEWS=N\&PAGE=fulltext\&D=med4 $\& A N=10029398$

36 Belsley DA, Kuh E, Welsch RE. Regression diagnostics: identifying influential data and sources of collinearity. New York: Wiley, 1980.

37 Reuben D, Magasi S, McCreath HE, et al. Motor assessment using the NIH toolbox. Neurology 2013;80(Suppl 3):S65-75.

38 Holland AE, Spruit MA, Troosters T, et al. An official European Respiratory Society/ American Thoracic Society technical standard: field walking tests in chronic respiratory disease. Eur Respir J 2014;44:1428-46.

39 Improving Long-Term Outcomes Research for Acute Respiratory Failure. http://www. improvelto.com/instruments/ (accessed 14 Dec 2015).

40 Schneider AG, Lipcsey M, Bailey $M$, et al. Simple translational equations to compare illness severity scores in intensive care trials. J Crit Care 2013;28:85.e1-8. 